\title{
Shaping ability of four single-file systems in the instrumentation of second mesiobuccal canals of three-dimensional printed maxillary first molars
}

\author{
Fulu Xu ${ }^{1,2 \#}$, Yuerong Zhang ${ }^{2,3 \#}$, Yongchun $\mathrm{Gu}^{4}$, Yifan Ping ${ }^{1,2}$, Ruyu Zhou ${ }^{2}$, Juan Wang ${ }^{1,2}$ \\ ${ }^{1}$ Department of Endodontics and Operative Dentistry, The Affiliated Stomatological Hospital of Nanjing Medical University, Nanjing, China; \\ ${ }^{2}$ Jiangsu Province Key Laboratory of Oral Diseases, Jiangsu Province Engineering Research Center of Stomatological Translational Medicine, \\ Nanjing, China; ${ }^{3}$ Department of General Dentistry, The Affiliated Stomatological Hospital of Nanjing Medical University, Nanjing, China; \\ ${ }^{4}$ Department of Dentistry, The Ninth People's Hospital of Suzhou, China \\ Contributions: (I) Conception and design: J Wang; (II) Administrative support: Y Zhang, J Wang; (III) Provision of study materials or patients: Y \\ Zhang, J Wang; (IV) Collection and assembly of data: Y Zhang, F Xu; (V) Data analysis and interpretation: Y Zhang, F Xu; (VI) Manuscript writing: \\ All authors; (VII) Final approval of manuscript: All authors. \\ "These authors contributed equally to this work. \\ Correspondence to: Juan Wang, PhD, DDS. The Affiliated Stomatological Hospital of Nanjing Medical University, Hanzhong Road $136^{\text {th }}$, Nanjing \\ 210029, China. Email: candy1249@126.com.
}

Background: This study evaluated and compared the shaping ability of four advanced single-file nickeltitanium (NiTi) systems during the preparation of curved second mesiobuccal (MB2) canals in maxillary first molar replicas fabricated by three-dimensional (3D) printing via micro-computed tomography (Micro-CT) imaging.

Methods: A total of 60 3D-printed maxillary first molar replicas were constructed from one extracted tooth, with an angle of curvature ranging from $15^{\circ}$ to $25^{\circ}$. The MB2 canals from these 60 replicas were divided into 4 groups of 15 replicas according to the canal instrumentation system used, namely, Waveone gold (WOG), Reciproc blue (RCB), XP-endo shaper (XPS) and M3-L. The specimens were scanned before and after preparation using Micro-CT. The pre- and post-instrumentation images of each specimen were superimposed, and the amount of resin removed, the change in surface area, the canal transportation, and centering ability were assessed using the Mimics software. Instrumentation time was also recorded. One-way analysis of variance and least significant difference (LSD) tests were used to statistically compare the groups. The significance level was set at $5 \%$.

Results: Instrumentation time with M3-L was significantly longer than the other systems $(\mathrm{P}<0.05)$. The amount of resin removed and the change in surface area generated by the 4 systems were different at the apical, middle, and coronal thirds, and the total canal $(\mathrm{P}<0.05)$. Overall, WOG and XPS resulted in the less change than RCB and M3-L. There was no significant difference among the groups at the middle third regarding canal transportation and centering ability $(\mathrm{P}>0.05)$. However, a significant difference was found at the apical level $(\mathrm{P}<0.05)$, where RCB showed the poorest centering ability and the highest canal transportation $(\mathrm{P}<0.05)$. In addition, XPS resulted in the least canal transportation $(\mathrm{P}<0.05)$ at the coronal level, while there was no significant difference between the four groups in terms of centering ability.

Conclusions: The M3-L instrument required more time to prepare the curved MB2 canals compared with the other systems. Overall, WOG and XPS showed the least resin removal and surface area change. M3-L, XPS, and WOG instruments respected the original canal curvature better than RCB files.

Keywords: Single-file NiTi systems; three-dimensional printing (3D printing); second mesiobuccal canals (MB2 canals); shaping ability 
Submitted Jul 02, 2021. Accepted for publication Aug 26, 2021.

doi: 10.21037/atm-21-3855

View this article at: https://dx.doi.org/10.21037/atm-21-3855

\section{Introduction}

Anatomical complexities and variations of the root canal system present a great challenge for clinicians, with a higher possibility of complications, such as ledges, zips, perforations and canal transportation during the process of canal shaping $(1,2)$, thus affecting the treatment outcomes $(3,4)$. In maxillary first molars, the prevalence of second mesiobuccal canals (MB2) has been reported ranging from 48.0-97.6\% among the regions, and the canal orifice is frequently covered by a thick dentine shelf (5). In addition, the MB2 canal is usually narrow with one or two abrupt curvatures in the coronal middle thirds of the canal (6-8). Studies have found that even under the guidance of the dental operating microscope, only less than $80 \%$ of MB2 canals can be successfully negotiated using hand files (8). Moreover, there is a higher risk of file fracture during the preparation of the curved and tiny MB2 canals due to cyclic fatigue and torsional stress $(6,7)$. Therefore, studies exploring methods for the safe and effective negotiation and preparation of the MB2 canal are crucial.

Recently, single-file nickel-titanium (NiTi) systems with varying thermomechanical manufacturing, geometric designs, and motion kinematics (reciprocating/rotation) were introduced into the endodontic market. The application of single-file NiTi systems can shorten the instrumentation time and decrease the risk of crosscontamination, thereby improving clinical efficiency (9). Simultaneously, experiments demonstrated that this latter system did not compromise canal cleanliness compared with the full sequence rotary NiTi system (10). In fact, there is evidence showing that the single-file reciprocating system Reciproc 25 instrument was $32 \%$ more effective than hand files in negotiating MB2 canals to full working length. This further highlights the advantage of single-file NiTi systems in the preparation of intricate, narrow, and curved MB2 canals (6).

WaveOne Gold (WOG; Dentsply Maillefer, Ballaigues, Switzerland) and Reciproc Blue (RCB; VDW, Munich, Germany) are two brands of novel single-file systems operated in a reciprocation movement. WOG combines the metallurgical improvements of gold wire and thermal treatment, and exhibits a unique off-centered parallelogram cross-sectional design with 2 cutting edges (1-3,11-15). RCB is manufactured by an innovative heat treatment inducing a visible titanium oxide layer, giving it a blue color and presents a S-shape cross section with 2 cutting blades (1,13-18).

XP-endo Shaper (XPS; FKG Dent ire SA, La Chaux-deFonds, Switzerland) and M3-L (Yirui, China) are another two single-file systems, but operations in rotary movement. The XPS instrument takes on a snake-shaped form with a triangular cross-section, and combines the MaxWire alloy technology and the Booster tip with a six-blade tip $(12,16,17,19-21)$. M3-L is made of heat-treated alloy (M-wire), and has a double S-shape cross-section with 2 cutting flutes and a non-cutting tip (22). To the best of our knowledge, few studies have evaluated the shaping abilities of the above-mentioned single-file NiTi systems on the instrumentation of MB2 canals.

To date, such canal shaping studies are commonly performed on extracted teeth as it allows for the optimal simulation of the microenvironment in a clinical scenario (3,7,23-26). However, the associated disadvantages include bioethical concerns, absence of standardization, limited access, and individual anatomic variations $(1,23)$.

Three-dimensional (3D) printing is an innovative rapid prototyping technology that relies on two-dimensional data, post-processing tools, and algorithms to restructure and edit multiple planes to eventually form a $3 \mathrm{D}$ model and realize the overall molding. In recent years, with the rapid development of materials and the assistance of micro-computed tomography (Micro-CT) and cone-beam computed tomography (CBCT), 3D-printing technology has successfully manufactured tooth replicas that can precisely replicate both the external shape of natural teeth and the internal anatomy of the natural root canal system. The replicas have the advantages of consistency, convenience, reproducibility, and repeatability (27). Gok et al. and Ordinola-Zapata et al. showed that 3D printed canal replicas can be an ideal model to evaluate the performance of different canal obturation techniques and the shaping abilities of different instruments $(23,27-29)$. In this regard, there has been no report evaluating the root canal preparation of $\mathrm{MB} 2$ canals in maxillary first molars fabricated by $3 \mathrm{D}$ printing so far. 
Therefore, this study evaluated the shaping ability and efficiency of four novel thermally-treated single-file NiTi systems (WOG, RCB, XPS, and M3-L) using the curved MB2 canals of 3D printed maxillary first molars. This will provide a theoretical basis for selecting the best strategy of MB2 instrumentation. The null hypothesis tested was that there will be no significant difference between the four single-file systems in terms of the parameters tested. We present the following article in accordance with the MDAR reporting checklist (available at https://dx.doi.org/10.21037/ atm-21-3855).

\section{Methods}

\section{Specimen selection and micro-CT scanning}

Ethical approval was obtained from the Affiliated Stomatological Hospital of Nanjing Medical University, Nanjing, China (Reference No. PJ2019-057-001). Informed consent was provided by all participants. All procedures performed in this study involving human participants were in accordance with the Declaration of Helsinki (as revised in 2013).

An initial pool of 118 intact human permanent maxillary first molars extracted for reasons not related to this study were collected. After removal of calculus and the soft tissue remnants on the root surface, the teeth were stored in $10 \%$ neutral buffered formalin solution.

The teeth were scanned using a micro-CT device (SkyScan 1174v2; Bruker-microCT, Kontich, Belgium) with $50 \mathrm{kV}, 800 \mu \mathrm{A}$, and $360^{\circ}$ rotation around the vertical axis, with a $0.7^{\circ}$ rotation step using a $1.0 \mathrm{~mm}$ aluminum filter, producing images with a $36.3 \mu \mathrm{m}$ voxel size. Subsequently, the acquired projection images in "TIFF" format were reconstructed into 500-600 cross-sectional slices with NRecon (v.1.6.9 software, Bruker-microCT) as follows: $30 \%$ beam hardening correction, sharpening of $40 \%$, smoothing of 3, and a ring artifact reduction of 4 . All images were then transferred to Mimics (v.19.01 software, ImageWorks Resinise, Belgium) in BMP format, and the 3D models of the roots and pulp cavities were reconstructed based on adjusting threshold segmentations manually, allowing visualization of the internal structure of each mesiobuccal root canal.

One representative maxillary first molar was selected according to the following inclusion criteria: (I) a type III canal configuration system (based on the classification by Weine et al.) in the mesiobuccal root (i.e., 2 separate canals and 2 separate apical foramina) (30); (II) the MB2 canal presents with a curvature ranging from $15^{\circ}$ to $25^{\circ}$, according to Schneider's method (31), and the working length between 16 and $18 \mathrm{~mm}$; (III) the MB2 canal has a fully formed apex and no sign of cracks; and (IV) no previous endodontic treatment and the absence of calcifications or internal absorption.

\section{$3 D$ printing of the maxillary first molar}

The 3D model of the selected tooth was transferred to the 3D-printed model repair software Magics (v.22.0, Imageworks Resinise, Belgium) in standard tessellation language (stl) format to prepare pulpal access cavity by applying Boolean Operations without damaging the delicate internal structure of the root canal. Subsequently, 60 replicas of the tooth were obtained in $16-\mu \mathrm{m}$ resolution using a modified urethane acrylate photopolymer (VisiJet Crystal, 3D Systems, Rock Hill, SC, USA) in a ProJet HD 3510 3D printer (3D System Rock Hill, SC, USA).

A sample size of 15 replicas in each group was calculated to be sufficient to stipulate significant data differences (an alpha-type error of $0.05,95 \%$ power, and a ratio of $\mathrm{N} 2 / \mathrm{N} 1$ up to 1$)$.

\section{Root canal instrumentation}

The 60 replicas were randomly assigned to 4 experimental groups $(n=15)$ according to the instrumentation system used. The MB2 canals were negotiated with size \#10 K-file (Dentsply Maillefer) until the file tip was just visible exiting the apical foramen. The working length (WL) was determined by deducting $1 \mathrm{~mm}$ from that value.

After the WL determination, a single operator, proficient in the use of all $4 \mathrm{NiTi}$-systems, performed the instrumentation in all groups. The NiTi files were driven by the electric motor (X-smart Plus, Dentsply Maillefer) in a continuous clockwise rotation (for M3-L and XPS) or in a reciprocating motion (for WOG and $\mathrm{RCB}$ ) according to the manufacturer's recommendations as follows, and then discarded after preparation of one MB2 canal.

* Group 1. The WOG Primary instrument (size 25; 0.07 variable taper) was operated at $350 \mathrm{rpm}$ using the "WAVEONE ALL" mode in the instrumentation of MB2 canals.

* Group 2. The RCB instrument (size 25; 0.08 variable taper) was operated at $300 \mathrm{rpm}$ with the 
"RECIPROC ALL" program to instrument the MB2 canals.

* Group 3. The XPS instrument (size 27; 0.01 variable taper) was operated with a rotational speed of $800 \mathrm{rpm}$ and a torque of $1.0 \mathrm{Ncm}$.

* Group 4. The M3-L2 instrument (size 25; 0.065 variable taper) was operated with a rotational speed of $500 \mathrm{rpm}$ and a torque of $2.0 \mathrm{Ncm}$.

In all groups, the instrument was advanced apically by applying light apical pressure with an in-and-out pecking motion of approximately $3 \mathrm{~mm}$ amplitude and a gentle brushing motion against the canal walls until reaching the WL. After each cycle of three pecking motions, the canal was irrigated with a total of $5.0 \mathrm{~mL} 2.5 \% \mathrm{NaOCl}$ during instrumentation, and the instrument was retrieved from the canal and cleaned fluted with sterile gauze.

At the end of chemo-mechanical instrumentation, all canals were filled with $5.0 \mathrm{~mL} 2.5 \% \mathrm{NaOCl}$, followed by a final rinse using $5.0 \mathrm{~mL}$ saline solution. The irrigation protocol was performed using a 30-G NaviTip needle (Ultradent, South Jordan, UT) placed $2 \mathrm{~mm}$ from the apical foramen. Subsequently, the specimens were dried with absorbent paper points.

\section{Micro-CT imaging and evaluation methodology}

Each specimen was scanned twice using Micro-CT before and after canal preparation following the same scanning and reconstruction protocols as those established initially. Pre- and post-operative images were superimposed using the $3 \mathrm{D}$ registration function of the DataViewer (v.1.5.1 software, Bruker micro-CT). The Mimics software version 19.01 (ImageWorks Resinise, Belgium) was then used to calculate the quantitative morphologic parameters and construct visual 3D models of the root and canal. The parameters evaluated were as follows: the amount of resin removed and the change in surface area; and the canal transportation and centering ability at three crosssectional levels that correspond to the apical, middle, and coronal thirds of the root.

\section{Instrumentation time}

The time required to complete instrumentation was recorded using a stopwatch and included active shaping of each root canal and excluded the time taken for cleaning flutes of the instruments and irrigation. The total time for canal preparation was calculated by adding the recorded times in the same experimental group for each canal.

\section{The amount of resin removed and the change in surface area}

The global threshold module was applied to generate separated binary images of the canal region and root resin by manually adjusting the threshold range according to their density difference. The 3D evaluation of the volume and surface area was performed before and after instrumentation, extending from the orifice to the apex of MB2 canals by integrating the regions of interest in all of the cross sections. The amount of resin removed and the change in surface area for each MB2 canal in the whole canal, and the coronal, middle, and apical thirds were calculated by subtracting the values for un-instrumented canals from those recorded for the instrumented counterparts.

\section{Canal transportation}

Root canal transportation at the apical, middle, and coronal thirds was measured in millimeters after superimposing the corresponding pre- and post-instrumentation crosssectional images, according to the following formula as described by Gambill et al. (32):

$$
\text { Degree of canal transportation }=(\mathrm{D} 1-\mathrm{D} 2)-(\mathrm{M} 1-\mathrm{M} 2)
$$

where D1 and D2 represent the least distance from the distal periphery of the root to the distal periphery of the un-instrumented and instrumented canal, respectively, and M1 and M2 represent the least distance from the mesial periphery of the root to the mesial periphery of the uninstrumented and instrumented canal, respectively (Figure 1).

Pre-and post-instrumentation superimposed images were compared to determine the presence or absence of transportation. According to this formula, 0 indicates no canal transportation, and values other than 0 represent transportation and its direction. Positive values indicate that transportation occurred towards the furcation region (distal), and negative values indicate transportation away from the furcal zone (mesial). The tendency of transportation direction was assessed from the results obtained for each specimen.

\section{Centering ability}

The ability of the instrument to remain in a central position within the root canal was defined as the centering ability, 
according to Gambill et al. (32). This was calculated using the pre- and post-instrumentation superimposed images at the apical, middle, and coronal thirds according to the following equation:

$$
\begin{aligned}
\text { Centering ability } & =(\mathrm{M} 1-\mathrm{M} 2) /(\mathrm{D} 1-\mathrm{D} 2), \\
& \text { if }(\mathrm{M} 1-\mathrm{M} 2)<(\mathrm{D} 1-\mathrm{D} 2) ; \\
\text { or Centering ability } & =(\mathrm{D} 1-\mathrm{D} 2) /(\mathrm{M} 1-\mathrm{M} 2), \\
& \text { if }(\mathrm{D} 1-\mathrm{D} 2)<(\mathrm{M} 1-\mathrm{M} 2)
\end{aligned}
$$

Accordingly, a result of 1 indicates the optimal centering ability, and the closer the value is to 0 , the lesser the ability of the instrument to remain in its central position within
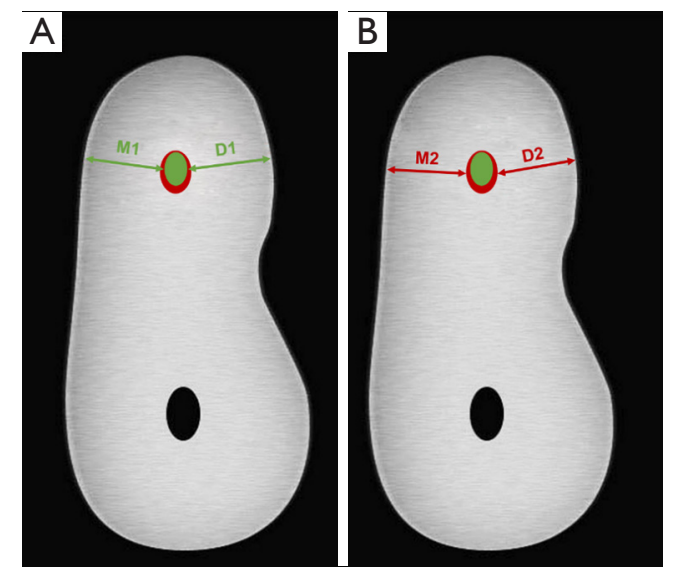

Figure 1 Diagrammatic representation of mesiobuccal root sections (green: preoperative second mesiobuccal (MB2) canal, red: postoperative canal) for assessing canal transportation and centering ability. (A) annotation of the preoperative least distance; (B) annotation of the postoperative least distance. the root canal.

\section{Statistical analysis}

All statistical analyses were performed with SPSS statistics software Version 23 (SPSS Inc., Chicago, IL, USA). The Shapiro-Wilk test was used to evaluate the normal distribution of the data. One-way analysis of variance was used to assess differences among the 4 groups at the apical, middle, and coronal thirds. In cases where significant differences are detected, post hoc pair-wise comparisons were performed with the least significant difference (LSD) test. The significance level was set at $5 \%(\mathrm{P}<0.05)$.

\section{Results}

The mesial view of the maxillary first molar with a type III canal configuration system in the mesiobuccal root and the replica in 3D construction are shown in Figure 2.

Table 1 shows the mean values of the instrumentation time of each group. The M3-L group exhibited the longest instrumentation time, which was statistically significantly different from XPS, WOG, and RCB $(\mathrm{P}<0.05)$.

Figure 3 shows the representative images of the internal anatomy of MB2 in the four groups, pre- and postinstrumentation, and in combination. The mean values of the amount of resin removed and the changes in surface area in the whole canal, and in the coronal, middle, and apical thirds of each group are depicted in Tables 2,3. The amount of resin removed and the changes in surface area were significantly lower in WOG compared to RCB, XPS,
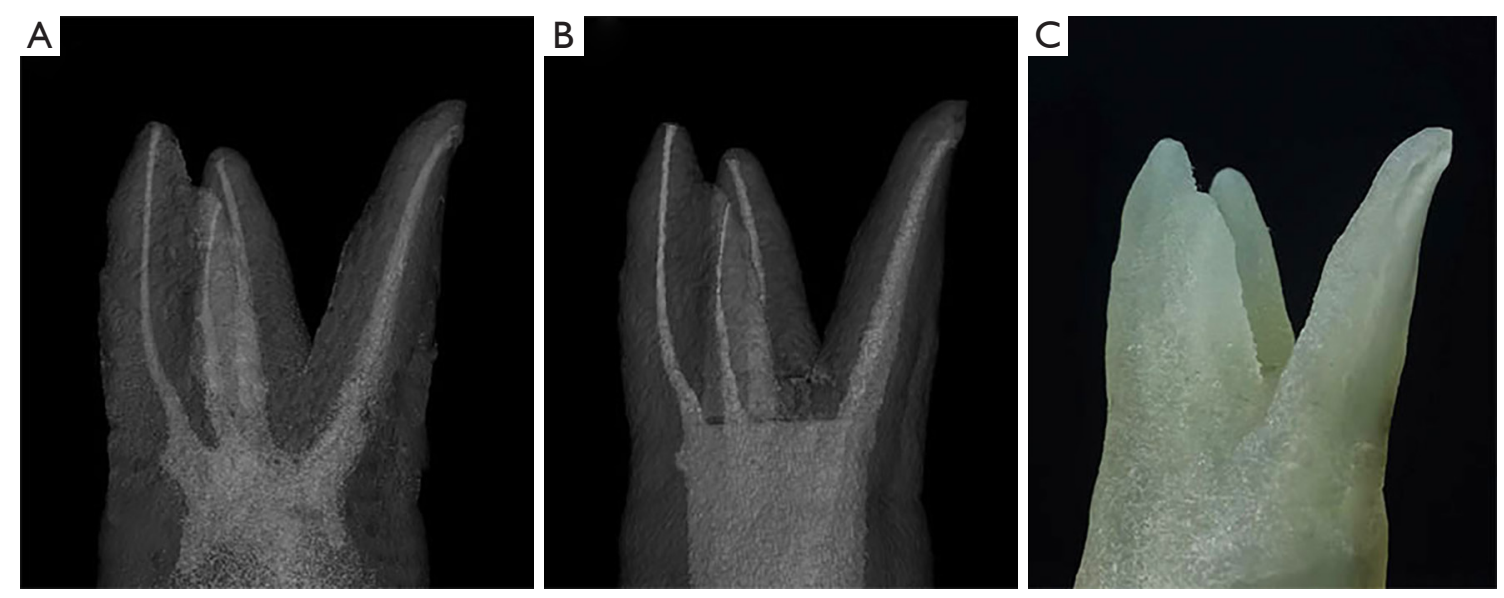

Figure 2 Mesial view of the maxillary first molar with a type III in mesiobuccal root. (A) Micro-CT reconstruction image of the prototype; (B) micro-CT reconstruction image of the replica after access cavity preparation; (C) the $3 \mathrm{D}$ printed simulated maxillary first molar model. 
Table 1 Differences in instrumentation time (mean \pm standard deviation) of preparing second mesiobuccal (MB2) canals in maxillary first molars with the instrument systems

\begin{tabular}{lcccc}
\hline Variable & Waveone gold & Reciproc blue & XP-endo Shaper & M3-L \\
\hline $\mathrm{N}$ & 15 & 15 & 15 & 15 \\
Working times (s) & $6.95 \pm 1.32^{\mathrm{b}}$ & $6.99 \pm 1.27^{\mathrm{b}}$ & $6.33 \pm 0.74^{\mathrm{b}}$ & $13.54 \pm 0.97^{\mathrm{a}}$ \\
\hline
\end{tabular}

Same superscript letters indicated no statistical differences among groups (one-way analysis of variance post hoc LSD test, $\mathrm{P}<0.05$ ).

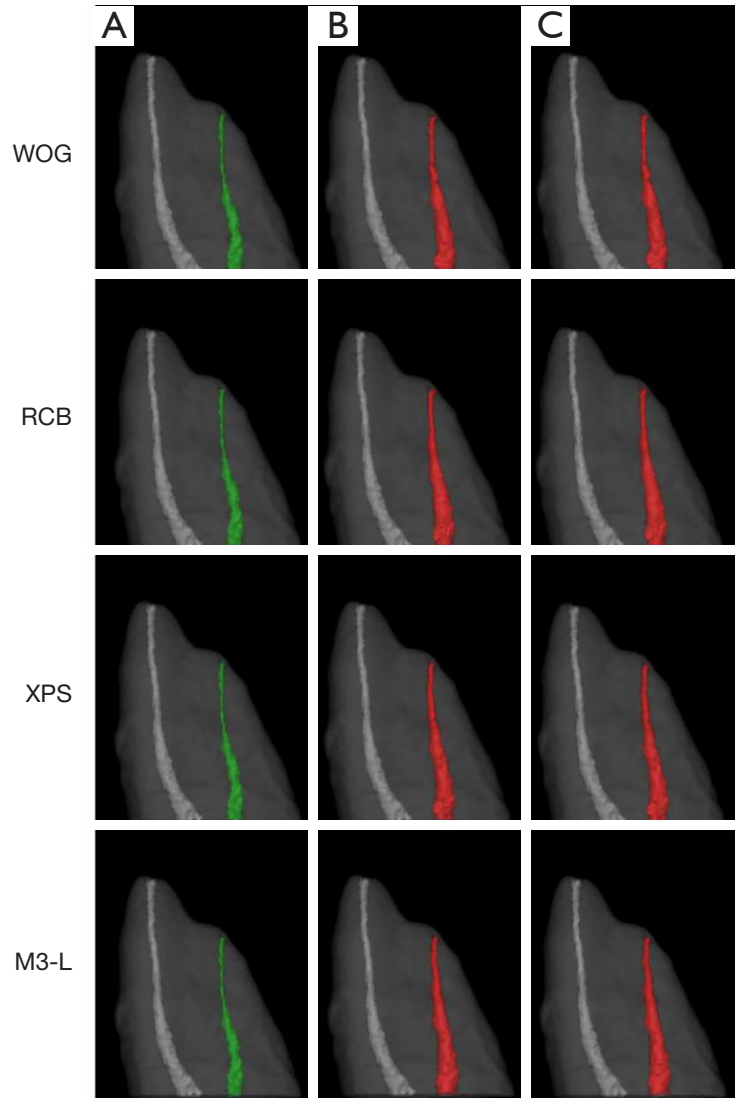

Figure 3 Three-dimensional reconstructions of second mesiobuccal (MB2) canals representative of the Waveone Gold (WOG), Reciproc Blue (RCB), XP-endo Shaper (XPS), and M3-L groups. (A) Preoperative reconstructions (green); (B) postoperative reconstructions (red); and (C) superimposed reconstructions.

and $\mathrm{M} 3-\mathrm{L}$ in the apical third $(\mathrm{P}<0.05)$. In the middle third, RCB presented higher values compared to XPS and WOG $(\mathrm{P}<0.05)$. For the coronal third, both RCB and M3-L were associated with higher values, followed by WOG, and then XPS $(\mathrm{P}<0.05)$. Overall, XPS and WOG caused significantly less resin removal and surface area changes in the entire canal compared with RCB and M3-L $(\mathrm{P}<0.05)$.

The canal transportation results are summarized for the coronal, middle, and apical thirds after instrumentation with WOG, RCB, XPS, and M3-L (Table 4). RCB had higher values of transportation in the apical third compared to M3-L, XPS, and WOG $(\mathrm{P}<0.05)$. As for the coronal third, XPS resulted in significantly less canal transportation than WOG, RCB, and M3-L $(\mathrm{P}<0.05)$. In addition, no statistically significant differences were observed between the groups in the middle third $(\mathrm{P}>0.05)$. The representative images of MB2 canal transportation before and after preparation performed with the 4 instrumentation groups are presented in Figure 4.

The mean values of centering ability for the 4 groups at the 3 reference levels are depicted in Table 5. RCB had a significantly poorer ability to maintain within the central axis of the MB2 canal compared to M3-L, XPS, and WOG in the apical third $(\mathrm{P}<0.05)$, and no significant differences were observed among the 4 groups at the middle or coronal levels $(\mathrm{P}>0.05)$.

In terms of safety of the experimental NiTi systems, no file fractures nor aberrations, such as zips and perforations, occurred. All tested NiTi files reached the full WL in all instrumentation groups of MB2 replicas in this study.

\section{Discussion}

Improvements in the mechanized instrumentation systems have been continually made to correspond to the anatomic challenges of the root canal system. In the present study, the 3D-printed maxillary first molars with unified curved MB2 canals were used to evaluate the shaping abilities of 4 novel single-file systems with different manufacturing methods, designs, and kinematics. On the basis of the results in the current study, the hypothesis that there is no difference between the four single-file systems in terms of the parameters tested was partially rejected.

Many studies have confirmed the anatomical complexities and variations of the mesiobuccal root canal system (single or multiple canals with intercanal communications, isthmus, accessory, or apical ramifications) $(5,6,33,34)$. Weine et al. 
Table 2 Removed resin volume (mean \pm standard deviation) in the apical, middle and coronal thirds, and the whole canal of second mesiobuccal (MB2) in maxillary first molars after preparing with the instrument systems

\begin{tabular}{|c|c|c|c|c|c|}
\hline Area analyzed & Initial volume $\left(\mathrm{mm}^{3}\right)$ & \multicolumn{4}{|c|}{ Volumetric changes $\left(\mathrm{mm}^{3}\right)(\mathrm{N}=15)$} \\
\hline Apical third & 0.26 & $0.10 \pm 0.02^{b}$ & $0.15 \pm 0.09^{a}$ & $0.17 \pm 0.05^{\mathrm{a}}$ & $0.16 \pm 0.03^{a}$ \\
\hline Middle third & 0.50 & $0.30 \pm 0.06^{b}$ & $0.42 \pm 0.12^{\mathrm{a}}$ & $0.34 \pm 0.09^{b}$ & $0.35 \pm 0.07^{\mathrm{b}}$ \\
\hline Coronal third & 1.00 & $0.48 \pm 0.04^{b}$ & $0.62 \pm 0.10^{\mathrm{a}}$ & $0.33 \pm 0.08^{c}$ & $0.60 \pm 0.07^{\mathrm{a}}$ \\
\hline
\end{tabular}

Same superscript letters indicated no statistical differences among groups for each level analysed (one-way analysis of variance post hoc LSD test, $\mathrm{P}<0.05)$.

Table 3 Change in surface area (mean \pm standard deviation) in the apical, middle, and coronal thirds, and the whole canal of second mesiobuccal (MB2) in maxillary first molars after preparing with the instrument systems

\begin{tabular}{|c|c|c|c|c|c|}
\hline Area analyzed & Initial surface area $\left(\mathrm{mm}^{2}\right)$ & \multicolumn{4}{|c|}{ Change in surface area $\left(\mathrm{mm}^{2}\right)(\mathrm{N}=15)$} \\
\hline Apical third & 3.30 & $0.49 \pm 0.13^{b}$ & $0.78 \pm 0.44^{\mathrm{a}}$ & $0.83 \pm 0.21^{\mathrm{a}}$ & $0.81 \pm 0.16^{a}$ \\
\hline Middle third & 4.56 & $1.22 \pm 0.19^{b}$ & $1.64 \pm 0.50^{\mathrm{a}}$ & $1.31 \pm 0.29^{b}$ & $1.43 \pm 0.22^{\mathrm{ab}}$ \\
\hline Coronal third & 7.91 & $0.94 \pm 0.10^{b}$ & $1.32 \pm 0.26^{\mathrm{a}}$ & $0.60 \pm 0.19^{c}$ & $1.28 \pm 0.18^{a}$ \\
\hline
\end{tabular}

Same superscript letters indicated no statistical differences among groups for each level analysed (one-way analysis of variance post hoc LSD test, $\mathrm{P}<0.05)$.

Table 4 Canal transportation (mean \pm standard deviation) in the apical, middle, and coronal thirds of second mesiobuccal (MB2) canals in maxillary first molars after preparing with the instrument systems

\begin{tabular}{|c|c|c|c|c|c|c|c|}
\hline Instrument system & $\mathrm{N}$ & \multicolumn{2}{|c|}{ Apical-third } & \multicolumn{2}{|c|}{ Middle-third } & \multicolumn{2}{|c|}{ Coronal-third } \\
\hline Waveone gold & 15 & $-0.04 \pm 0.04^{b}$ & -0.10 to 0.00 & $-0.06 \pm 0.04^{\mathrm{a}}$ & -0.15 to 0.00 & $0.33 \pm 0.03^{\mathrm{a}}$ & 0.29 to 0.38 \\
\hline Reciproc blue & 15 & $-0.08 \pm 0.05^{\mathrm{a}}$ & -0.15 to 0.00 & $-0.05 \pm 0.07^{\mathrm{a}}$ & -0.13 to 0.12 & $0.30 \pm 0.05^{a}$ & 0.23 to 0.39 \\
\hline XP-endo shaper & 15 & $-0.02 \pm 0.04^{b}$ & -0.09 to 0.05 & $-0.07 \pm 0.04^{a}$ & -0.15 to 0.00 & $0.24 \pm 0.06^{b}$ & 0.10 to 0.31 \\
\hline
\end{tabular}

Same superscript letters indicated no statistical differences among groups for each level analysed (one-way analysis of variance post hoc LSD test, $\mathrm{P}<0.05)$.

and Imura et al. suggested that in many cases, if the single foramen in type I and II was adequately cleaned, shaped and filled, then the chances of success would be excellent. In contrast, type III configuration is a challenging task for endodontic treatment, since they are prone to result in the failure of treatment if one of the two canals in mesiobuccal root is not properly treated $(30,35)$. Therefore, in order to seclude and minimize the influence of complex canal structures, and ensuring a better standardization of specimens, the maxillary first molar with type III canal configuration (Weine et al.'s classification) was chosen.

$3 \mathrm{D}$ printing is a novel technology that has been broadly introduced applied in dentistry in the past decade to fabricate duplicate physical objects based on its virtual models and offer support for research tasks (23,29,36-38). So far, various appliances have been printed, such as drill 
Page 8 of 12
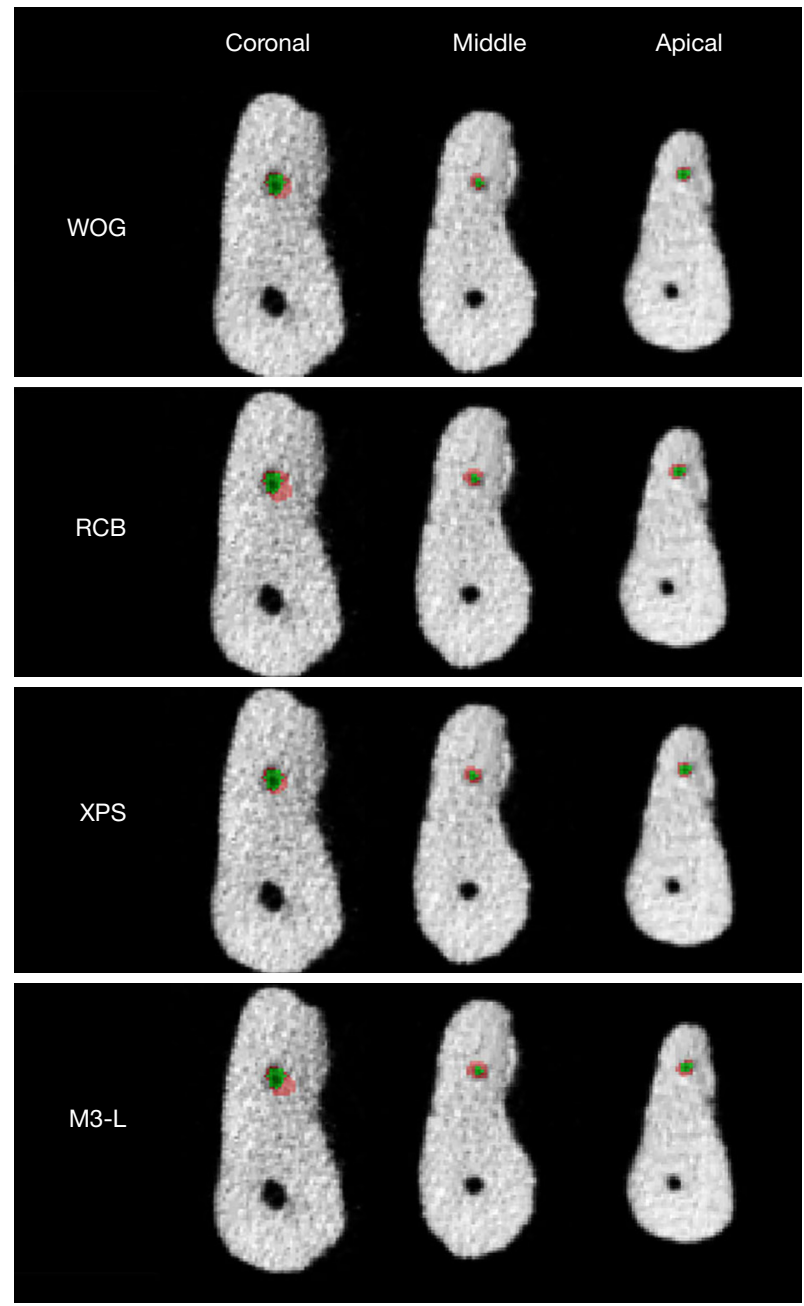

Figure 4 Representative cross sections of superimposed images showing the effect of canal preparation with the four groups at the apical, middle, and coronal levels (green: preoperative canal, red: postoperative canal).
Xu et al. Root canal preparation in 3D printed maxillary first molars

guides for dental implants, craniomaxillofacial implants, and physical tooth models for the diagnosis of atypical root morphology. Recent studies have proved the successful reproduction of narrow or complicated internal root canal structures in the physical tooth models, such as C-shaped canals or narrow canals $\left(30^{\circ}-40^{\circ}\right)$ in maxillary first premolars and mandibular first molars with resin materials $(27,39)$. The translucent resin used in the $3 \mathrm{D}$ printing can not only make the root canal more delicate and tangible (29), but also better simulate the physical properties and biological properties of natural dentin, thus improving the 'feel' of cutting during the preparation (23). In the current study, duplicate maxillary first molars with the same external and internal morphology as that of the natural tooth, were successfully printed 3-dimensionally through Micro-CT scanning and digital reconstruction, allowing for group comparing under the same anatomic conditions when evaluating the root canal instrumentation.

Micro-CT is considered an accurate, reliable, and noninvasive technique that permits visualization of different portions of canals investigated and has been extensively used in studies relevant to the shaping ability of instruments $(4,13,14,18,19,40-43)$. In this study, MicroCT was combined with the application of Mimics software to construct a three-dimensional model of MB2 root canals with extremely high resolution and fine details, allowing for qualitative and quantitative assessments of the behavior of experimental instruments.

Instrumentation time is one of the most important parameters to evaluate the shaping efficiency of instruments, which is susceptible to the preparation techniques used, operator experience and other details regarding the study design $(9,15,24,42)$. In our study, the parameter merely

Table 5 Centering ability (mean \pm standard deviation) in the apical, middle, and coronal thirds of second mesiobuccal (MB2) canals in maxillary first molars after preparing with the instrument systems

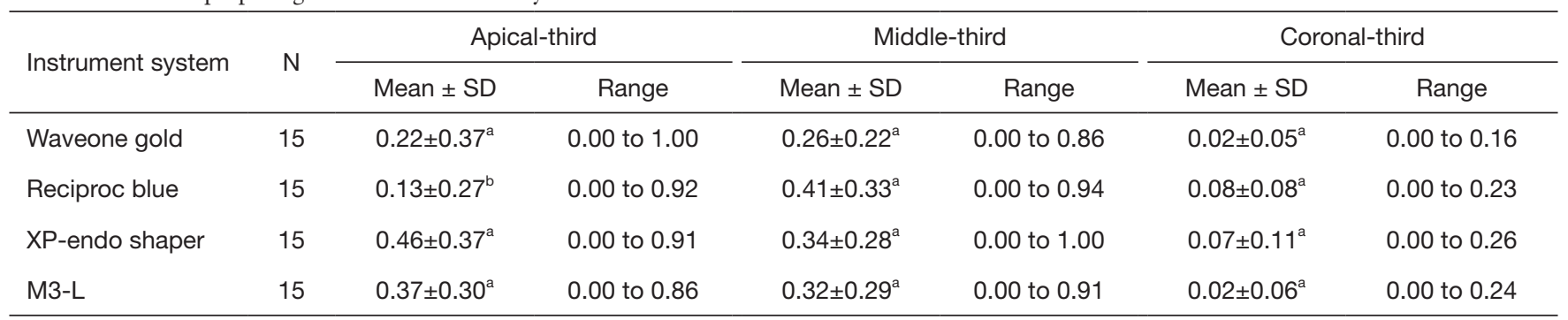

Same superscript letters indicated no statistical differences among groups for each level analysed (one-way analysis of variance post hoc LSD test, $\mathrm{P}<0.05)$. 
included active instrumentation for a more intuitive evaluation of the experimental instruments.

The shaping ability of endodontic instruments was evaluated by quantitative analysis of the amount of resin removal and changes in surface area. According to literature $(44,45)$, the cross-sectional design, cutting edge angle, surface treatment and motion kinematics are variables that may influence the above-mentioned parameters.

From our experimental results, we found that WOG $(0.07$ variable taper) presented significantly less resin removal and surface area changes than RCB (0.08 variable taper), M3-L (0.065 variable taper) and XPS (0.01) in the apical third, which may be explained by their different geometric designs and alloys. In general, canal instrumentation should preserve more dentin (minimally invasive) in the context of infection control, the removal of dentin wall, especially in the coronal thirds, can detrimentally impact tooth fracture resistance, thereby increasing the risk of root fracture. This study revealed that XPS was associated with more resin removal and surface area changes in the apical third while significantly less in the coronal third, compared with WOG, RCB and M3-L. This may be attributable to the relatively greater tip size $(0.27 \mathrm{~mm})$, a smaller degree of taper $(0.01)$ and more flexible geometric design of XPS, allowing it to shape the canal in three dimensions and reaching more untouched areas with minimal stress. In addition, the superelasticity of MaxWire alloy may also account for the superior performance of XPS. The present study discovered that RCB showed the greatest values of resin removal and surface area changes after shaping the MB2 canals in both middle and coronal thirds, which may probably ascribe to the greater taper of instruments.

During the preparation of curved root canals, due to the rigid nature of endodontic instruments, uneven stress distribution will generate on the lateral dentin wall, resulting in uneven dentin removal of the canal wall. Therefore, the instrumented canal sustainedly deviated from the original axis, which is known as canal transportation $(11,46-49)$. Severe canal transportation is associated with numerous adverse consequences (46,50). Clinical studies have shown that the dentin wall of MB2 is relatively thin towards the furcation area in the coronal thirds, which is prone to perforate if MB2 is excessively instrumented (7). Fortunately, no strip perforation occurred over the course of the present study. Although, in recent years, constant modifications have been made in the design of instruments and manufacturing processes, up till now, there are no instruments that are able to completely remain the central axis of the root canal without deviation.

Based on the findings of the study, all four groups of experimental instruments exhibited varying degrees of transportation in all measured sections, most of which tended to transport towards the furcation area (distal area) in the coronal third and away from the furcation area (mesial area) in the apical third. This result is in accordance with previous researches $(7,26)$.

In our study, the canal transportation of four groups was in line with the values reported in the literature, which were within the range from -0.14 to $0.41 \mathrm{~mm}$ (26). Many factors have been discussed as possible influencing factors to canal transportation, including the design of the instrument (size, taper), metallurgical properties and the root canal anatomy $(24,50)$. At apical and coronal thirds, canal transportation produced by XPS were significantly less than WOG, RCB, M3-L, which corroborating the results obtained by Poly et al. and Pacheco-Yanes et al. $(12,16)$. The flexibility of MaxWire alloy and its better adaption to the curved intracanal anatomy may partially explain the superior performance and mechanical behavior of XPS. In addition, the current study found through analysis that RCB provided comparable results with WOG and M3-L, only producing relatively more apical transportation. We speculated that the relatively large taper of RCB indicated a considerably larger core mass and rigidity, which may be one of the main causes for the lower maintenance of a centered canal with more deviations. Moreover, $\mathrm{Wu}$ et al. reported that an apical canal transportation greater than $0.3 \mathrm{~mm}$ could influence the sealing of root canals thus compromising the success of endodontic treatment (51). Fortunately, in this study, the mean values of canal transportation at the apical third all ranged from 0.02 to $0.08 \mathrm{~mm}$, which is much smaller than $0.3 \mathrm{~mm}$ after shaping with four experimental NiTi systems.

In terms of centering ability, no system is able to maintain perfectly centered canal preparation. However, based on our results, the mean values of centering ratios were all below 0.5 after instrumentation, and relatively lower values were unexpectedly observed at the coronal thirds. These results are in accordance with a previous study which compared the centering ability of RCB and XPS using resin blocks (16), while inconsistent with those studies regarding the centering ability of WOG, RCB, XPS and M3-L with the application of human teeth $(3,11,13,19,22)$. There are two speculations that might give rationale to explain this discrepancy. In the first place, the hardness of material and abrasion behavior are different between translucent resin and dentin, in other words, the stress (46). 


\section{Page 10 of 12}

In addition, another contributing factor is probably related to the differences in the study design, such as canals with different dimensions, sizes, and curvatures.

Based on the results of current research, we finally concluded that the instrumentation efficiency of M3-L is slightly lower than that of the other 3 NiTi systems. XPS and WOG preserved more dentin than RCB and M3-L in the preparation of $3 \mathrm{D}$-printed $\mathrm{MB} 2$ canals. Regarding the canal transportation and centering ability, XPS showed optimal performance at the apical and coronal thirds, while RCB provided comparable results with WOG and M3-L at the middle and coronal levels.

\section{Acknowledgments}

Funding: This research was funded by the Natural Science Foundation of Nanjing Health Commission (YKK20248) and the Scholarship from the 2018 Jiangsu Overseas Visiting Scholar Program for University Prominent Young \& Middle-Aged Teachers and Presidents (to JW).

\section{Footnote}

Reporting Checklist: The authors have completed the MDAR reporting checklist. Available at https://dx.doi. org/10.21037/atm-21-3855

Data Sharing Statement: Available at https://dx.doi. org/10.21037/atm-21-3855

Conflicts of Interest: All authors have completed the ICMJE uniform disclosure form (available at https://dx.doi. org/10.21037/atm-21-3855). The authors have no conflicts of interest to declare.

Ethical Statement: The authors are accountable for all aspects of the work in ensuring that questions related to the accuracy or integrity of any part of the work are appropriately investigated and resolved. Ethical approval was obtained from the Affiliated Stomatological Hospital of Nanjing Medical University, Nanjing, China (Reference No. PJ2019-057-001). Informed consent was provided by all participants. All procedures performed in this study involving human participants were in accordance with the Declaration of Helsinki (as revised in 2013).

Open Access Statement: This is an Open Access article distributed in accordance with the Creative Commons
Xu et al. Root canal preparation in 3D printed maxillary first molars

Attribution-NonCommercial-NoDerivs 4.0 International License (CC BY-NC-ND 4.0), which permits the noncommercial replication and distribution of the article with the strict proviso that no changes or edits are made and the original work is properly cited (including links to both the formal publication through the relevant DOI and the license). See: https://creativecommons.org/licenses/by-nc-nd/4.0/.

\section{References}

1. Keskin C, Demiral M, Sariyllmaz E. Comparison of the shaping ability of novel thermally treated reciprocating instruments. Restor Dent Endod 2018;43:e15.

2. Stringheta CP, Bueno CES, Kato AS, et al. Microcomputed tomographic evaluation of the shaping ability of four instrumentation systems in curved root canals. Int Endod J 2019;52:908-16.

3. Razcha C, Zacharopoulos A, Anestis D, et al. MicroComputed Tomographic Evaluation of Canal Transportation and Centering Ability of 4 Heat-Treated Nickel-Titanium Systems. J Endod 2020;46:675-81.

4. Haupt F, Pult JRW, Hülsmann M. Micro-computed Tomographic Evaluation of the Shaping Ability of 3 Reciprocating Single-File Nickel-Titanium Systems on Single- and Double-Curved Root Canals. J Endod 2020;46:1130-5.

5. Martins JNR, Alkhawas MAM, Altaki Z, et al. Worldwide Analyses of Maxillary First Molar Second Mesiobuccal Prevalence: A Multicenter Cone-beam Computed Tomographic Study. J Endod 2018;44:1641-9.e1.

6. Zuolo ML, Carvalho MC, De-Deus G. Negotiability of Second Mesiobuccal Canals in Maxillary Molars Using a Reciprocating System. J Endod 2015;41:1913-7.

7. Camargo EJ, Duarte MAH, Marques VAS, et al. The ability of three nickel-titanium mechanized systems to negotiate and shape MB2 canals in extracted maxillary first molars: a micro-computed tomographic study. Int Endod J 2019;52:847-56.

8. Görduysus MO, Görduysus M, Friedman S. Operating microscope improves negotiation of second mesiobuccal canals in maxillary molars. J Endod 2001;27:683-6.

9. Alfadley A, Alrajhi A, Alissa H, et al. Shaping Ability of XP Endo Shaper File in Curved Root Canal Models. Int J Dent 2020;2020:4687045.

10. Capar ID, Ertas H, Ok E, et al. Comparative study of different novel nickel-titanium rotary systems for root canal preparation in severely curved root canals. J Endod 2014;40:852-6. 
11. van der Vyver PJ, Paleker F, Vorster M, et al. Root Canal Shaping Using Nickel Titanium, M-Wire, and Gold Wire: A Micro-computed Tomographic Comparative Study of One Shape, ProTaper Next, and WaveOne Gold Instruments in Maxillary First Molars. J Endod 2019;45:62-7.

12. Poly A, AlMalki F, Marques F, et al. Canal transportation and centering ratio after preparation in severely curved canals: analysis by micro-computed tomography and double-digital radiography. Clin Oral Investig 2019;23:4255-62.

13. Elashiry MM, Saber SE, Elashry SH. Comparison of Shaping Ability of Different Single-File Systems Using Microcomputed Tomography. Eur J Dent 2020;14:70-6.

14. Duque JA, Vivan RR, Duarte MAH, et al. Effect of larger apical size on the quality of preparation in curved canals using reciprocating instruments with different heat thermal treatments. Int Endod J 2019;52:1652-9.

15. Bürklein S, Flüch S, Schäfer E. Shaping ability of reciprocating single-file systems in severely curved canals: WaveOne and Reciproc versus WaveOne Gold and Reciproc blue. Odontology 2019;107:96-102.

16. Pacheco-Yanes J, Gazzaneo I, Pérez AR, et al. Transportation assessment in artificial curved canals after instrumentation with Reciproc, Reciproc Blue, and XP-endo Shaper Systems. J Investig Clin Dent 2019;10:e12417.

17. Kabil E, Katić M, Anić I, et al. Micro-computed Evaluation of Canal Transportation and Centering Ability of 5 Rotary and Reciprocating Systems with Different Metallurgical Properties and Surface Treatments in Curved Root Canals. J Endod 2021;47:477-84.

18. Filizola de Oliveira DJ, Leoni GB, da Silva Goulart R, et al. Changes in Geometry and Transportation of Root Canals with Severe Curvature Prepared by Different Heattreated Nickel-titanium Instruments: A Micro-computed Tomographic Study. J Endod 2019;45:768-73.

19. Perez Morales MLN, González Sánchez JA, Olivieri Fernández JG, et al. TRUShape Versus XP-endo Shaper: A Micro-computed Tomographic Assessment and Comparative Study of the Shaping Ability-An In Vitro Study. J Endod 2020;46:271-6.

20. Lima CO, Barbosa AFA, Ferreira CM, et al. The impact of minimally invasive root canal preparation strategies on the ability to shape root canals of mandibular molars. Int Endod J 2020;53:1680-8.

21. Arıcan Öztürk B, Atav Ateş A, Fişekçioğlu E. Cone-Beam Computed Tomographic Analysis of Shaping Ability of XP-endo Shaper and ProTaper Next in Large Root Canals. J Endod 2020;46:437-43.

22. Chen X, Gu M. Center orientation in curved root canals after the preparation by three nickel- titanium rotary instruments. Chinese Journal of Practical Stomatology 2020.

23. Ordinola-Zapata R, Bramante CM, Duarte MA, et al. Shaping ability of reciproc and TF adaptive systems in severely curved canals of rapid microCT-based prototyping molar replicas. J Appl Oral Sci 2014;22:509-15.

24. Zhao D, Shen Y, Peng B, et al. Root canal preparation of mandibular molars with 3 nickel-titanium rotary instruments: a micro-computed tomographic study. J Endod 2014;40:1860-4.

25. Ceyhanli KT, Kamaci A, Taner M, et al. Shaping ability of two M-wire and two traditional nickel-titanium instrumentation systems in S-shaped resin canals. Niger J Clin Pract 2015;18:713-7.

26. Zhang Y, Liu J, Gu Y, et al. Analysis of second mesiobuccal root canal instrumentation in maxillary first molars with three nickel-titanium rotary instruments: a micro-computed tomographic study. Odontology 2021;109:496-505.

27. Gok T, Capar ID, Akcay I, et al. Evaluation of Different Techniques for Filling Simulated C-shaped Canals of 3-dimensional Printed Resin Teeth. J Endod 2017;43:1559-64.

28. Yahata Y, Masuda Y, Komabayashi T. Comparison of apical centring ability between incisal-shifted access and traditional lingual access for maxillary anterior teeth. Aust Endod J 2017;43:123-8.

29. Byun C, Kim C, Cho S, et al. Endodontic Treatment of an Anomalous Anterior Tooth with the Aid of a 3-dimensional Printed Physical Tooth Model. J Endod 2015;41:961-5.

30. Weine FS, Healey HJ, Gerstein H, et al. Canal configuration in the mesiobuccal root of the maxillary first molar and its endodontic significance. Oral Surg Oral Med Oral Pathol 1969;28:419-25.

31. Schneider SW. A comparison of canal preparations in straight and curved root canals. Oral Surg Oral Med Oral Pathol 1971;32:271-5.

32. Gambill JM, Alder M, del Rio CE. Comparison of nickeltitanium and stainless steel hand-file instrumentation using computed tomography. J Endod 1996;22:369-75.

33. Degerness RA, Bowles WR. Dimension, anatomy and morphology of the mesiobuccal root canal system in maxillary molars. J Endod 2010;36:985-9.

34. Martins JNR, Marques D, Silva EJNL, et al. Second mesiobuccal root canal in maxillary molars-A systematic review and meta-analysis of prevalence studies using 
Page 12 of 12

cone beam computed tomography. Arch Oral Biol 2020;113:104589.

35. Imura N, Hata GI, Toda T, et al. Two canals in mesiobuccal roots of maxillary molars. Int Endod J 1998;31:410-4.

36. Bhargav A, Sanjairaj V, Rosa V, et al. Applications of additive manufacturing in dentistry: A review. J Biomed Mater Res B Appl Biomater 2018;106:2058-64.

37. Dawood A, Marti Marti B, Sauret-Jackson V, et al. 3D printing in dentistry. Br Dent J 2015;219:521-9.

38. Barazanchi A, Li KC, Al-Amleh B, et al. Additive Technology: Update on Current Materials and Applications in Dentistry. J Prosthodont 2017;26:156-63.

39. Cui Z, Wei Z, Du M, et al. Shaping ability of protaper next compared with waveone in late-model three-dimensional printed teeth. BMC Oral Health 2018;18:115.

40. de Albuquerque MS, Nascimento AS, Gialain IO, et al. Canal Transportation, Centering Ability, and Dentin Removal after Instrumentation: A Micro-CT Evaluation. J Contemp Dent Pract 2019;20:806-11.

41. Rhodes JS, Ford TR, Lynch JA, et al. Micro-computed tomography: a new tool for experimental endodontology. Int Endod J 1999;32:165-70.

42. Bürklein S, Hinschitza K, Dammaschke T, et al. Shaping ability and cleaning effectiveness of two single-file systems in severely curved root canals of extracted teeth: Reciproc and WaveOne versus Mtwo and ProTaper. Int Endod J 2012;45:449-61.

43. Siqueira JF Jr, Pérez AR, Marceliano-Alves MF, et al. What happens to unprepared root canal walls: a correlative analysis using micro-computed tomography and histology/scanning electron microscopy. Int Endod J 2018;51:501-8.

44. Alberton CS, Tomazinho FSF, Calefi PS, et al. Influence

\section{Xu et al. Root canal preparation in 3D printed maxillary first molars}

of the Preparation Order in Four-Canal Maxillary Molars with WaveOne Gold System. J Endod 2020;46:1291-6.

45. Gergi R, Osta N, Bourbouze G, et al. Effects of three nickel titanium instrument systems on root canal geometry assessed by micro-computed tomography. Int Endod J 2015;48:162-70.

46. Hasheminia SM, Farhad A, Sheikhi M, et al. Cone-beam Computed Tomographic Analysis of Canal Transportation and Centering Ability of Single-file Systems. J Endod 2018;44:1788-91.

47. Peters OA. Current challenges and concepts in the preparation of root canal systems: a review. J Endod 2004;30:559-67.

48. Shivashankar MB, Niranjan NT, Jayasheel A, et al. Computed Tomography Evaluation of Canal Transportation and Volumetric Changes in Root Canal Dentin of Curved Canals Using Mtwo, ProTaper and ProTaper Next Rotary System-An In-vitro Study. J Clin Diagn Res 2016;10:ZC10-4.

49. Silva EJ, Tameirão MD, Belladonna FG, et al. Quantitative Transportation Assessment in Simulated Curved Canals Prepared with an Adaptive Movement System. J Endod 2015;41:1125-9.

50. Karabucak B, Gatan AJ, Hsiao C, et al. A comparison of apical transportation and length control between EndoSequence and Guidance rotary instruments. J Endod 2010;36:123-5.

51. Wu MK, Fan B, Wesselink PR. Leakage along apical root fillings in curved root canals. Part I: effects of apical transportation on seal of root fillings. J Endod 2000;26:210-6.

(English Language Editor: J. Teoh)
Cite this article as: Xu F, Zhang Y, Gu Y, Ping Y, Zhou R, Wang J. Shaping ability of four single-file systems in the instrumentation of second mesiobuccal canals of threedimensional printed maxillary first molars. Ann Transl Med 2021;9(18):1425. doi: 10.21037/atm-21-3855 